\title{
NILAI SOSIAL PENDAKIAN GUNUNG SEBAGAI SUMBER IDE PENCIPTAAN SENI LUKIS
}

\author{
Arif Satriyo Pambudi \\ Pascasarjana ISI Yogyakarta \\ Institut Seni Indonesia Yogyakarta \\ email : arifsatriyopambudi2@yahoo.com \\ Diterima : 2 April 2020. Disetujui : 30 April 2020. Dipublikasikan : 10 Juni 2020 \\ (O)2020 - DESKOVI Universitas Maarif Hasyim Latif. Ini adalah artikel dengan akses \\ terbuka di bawah lisensi CC BY 4.0 (https://creativecommons.org/licenses/by/4.0/)
}

\begin{abstract}
ABSTRAK
Tujuan penciptaan yaitu untuk memvisualisasikan nilai sosial pendakian gunung sebagai sumber ide penciptaan seni lukis. Proses penciptaan berpedoman kepada metode penciptaan seni berbasis praktik (Practice Based Research). Lukisan ini disajikan melalui gaya surealis. Lukisan yang dihasilkan berjumlah 6 buah dengan berbagai ukuran yaitu kebersamaan dengan ukuran $(100 \times 120 \mathrm{~cm})$, dan karya selanjutnya adalah terbongkar dengan ukuran $(80 \times 100 \mathrm{~cm})$, sumber kehidupan dengan ukuran $(80 \times 100 \mathrm{~cm})$,siang malam dengan ukuran (80 x $100 \mathrm{~cm})$ kesetaraan dengan ukuran $(80 \times 100 \mathrm{~cm})$, semut kecil dengan ukuran $(80 \times 110 \mathrm{~cm})$.
\end{abstract}

Kata kunci: Nilai Sosial, Pendakian Gunung, Seni Lukis, Surealis

\begin{abstract}
The purposes of creation is visualized the social value of mountain climbing as a source of painting creation ideas. The purposes of creation is guided by methods of practice-based research. This painting is presented in a surreal style. The paintings produced amounted to six pieces of various sizes, namely togetherness with sizes $(100 \times 120 \mathrm{~cm})$, and the next work is uncovered with size $(80 \times 100 \mathrm{~cm})$, source of life with size $(80 \times 100 \mathrm{~cm})$, day and night with sizes ( $80 \times 100 \mathrm{~cm})$ equality in sizes (80 x $100 \mathrm{~cm})$, small ants in sizes $(80 \times 110 \mathrm{~cm})$.

Keywords: Social Value, Mountaineering, Painting, Surrealist
\end{abstract}

\section{PENDAHULUAN}

Pendakian gunung adalah suatu bentuk kegiatan yang dilakukan di alam terbuka dengan melakukan perjalanan menaiki pegunungan (Abdurrahman, 2015:6). Mendaki gunung mempunyai nilai positif untuk menyalurkan minat dan bakat generasi muda yang senantiasa menginginkan hal-hal baru.

Melalui mendaki gunung ini generasi muda akan berkembang secara spontan dan dapat dipacu untuk memberikan rangsangan kepada jiwa muda yang suka akan tantangan, keuletan dan ketangkasan serta kemampuan untuk menghadapi tantangan melalui kegiatan yang positif (Abdurrahman, 2015:1).

Namun pada kenyataanya, berdasarkan kejadian yang telah penulis alami sendiri, kegiatan mendaki gunung juga memiliki nilai negative, yaitu kita akan mampu mengenali pribadi teman yang sebenarnya. Sebab, ketika kita mendaki gunung, beberapa karakter pribadi orang yang sebenarnya akan nampak karena situasi yang sedang dihadapi. Misalnya: Ada yang jujur/tidak jujur, ada yang setia kawan/ tidak setia kawan, ada yang egois/tidak egois, ada yang teliti/ceroboh.
Melalui kegiatan mendaki gunung, kita akan bisa lebih mengenal karakter pribadi seseorang yang sebenarnya. Sungguh sangat disayangkan jika kegiatan yang seharusnya lebih positif, justru akan memberikan kesan negative karena tingkah laku para pendaki yang seperti itu.

Hal inilah yang memberi inspirasi kepada penulis untuk mengangkat tema tentang nilai sosial pendakian gunung yang bertujuan untuk memvisualisasikan karya lukis yang akan dihasilkan dari pengamatan atas fenomena dalam kegiatan mendaki gunung

\section{Nilai Sosial}

Nilai-nilai sosial adalah nilai yang dianut oleh suatu masyarakat, mengenai apa yang dianggap baik dan apa yang dianggap buruk oleh masyarakat. sebagai contoh, orang menganggap menolong memiliki nilai baik, sedang mencuri bernilai buruk.

Nilai adalah sesuatu yang berharga, bermutu, menunjukkan kualitas, dan berguna bagi manusia. Sesuatu itu bernilai berarti sesuatu itu berharga atau berguna bagi kehidupan manusia.

Nilai sosial merupakan seperangkat sikap individu yang dihargai sebagai suatu kebenaran dan dijadikan standar bertingkah laku guna memperoleh 
kehidupan masyarakat yang demokratis dan harmonis (Raven dalam Zubaedi, 2005: 12).

Sesuatu dapat dikatakan mempunyai nilai ketika masyarakat masih menganggap bahwa sesuatu itu bermakna dan memiliki arti bagi masyarakatnya. Dengan demikian nilai sosial diartikan sesuatu, apakah itu seni, ilmu, barang, atau yang lain yang mempunyai makna, arti, atupun fungsi bagi masyarakatnya.

\section{Pendakian Gunung}

Pendakian gunung adalah suatu bentuk kegiatan yang dilakukan di alam terbuka dengan melakukan perjalanan menaiki pegunungan (Abdurrahman, 2015:6). Manfaat pendakian gunung dikemukakan oleh Aprilia (2017) yakni mendaki gunung bisa bermanfaat bagi mental serta membuat hidup lebih bahagia karena terhubung dengan alam dapat membawa kedamaian dan rasa nyaman.

Manfaat dari mendaki gunung juga dikemukakan oleh Anna (2017) bahwa meskipun mendaki gunung merupakan kegiatan melelahkan, kegiatan pendakian gunung dapat bermanfaat bagi kesehatan. Tidak hanya bagi kebugaran fisik, tetapi kegiatan ini dianggap efektif unutuk kesehatan mental. Manfaat kegiatan luar ruang seperti pendakian gunung, mulai dari mempertajam ingatan sampai memperbaiki mood. Mendaki gunung juga dapat mengurangi stres, membuat daya ingat lebih kuat, lebih kreatif, dan menciptakan rasa bahagia.

\section{METODE PENELITIAN}

Proses penciptaan berpedoman kepada metode penciptaan seni berbasis praktik (Practice Based Research). Penelitian artistik yang akan dilakukan mengacu kepada buku artistic research. Dalam buku Artistic research di jelaskan bahwa, "the starting point for artistic research is the open subjectivity of the researcher and her admission that she is the central research tool of the research".(Hannula, Souranta, vaden 2005).

Maka dari penjelasan tersebut menegaskan bahwa tingkat subjektifitas dalam artistic research bersifat terbuka atas peneliti, dan peneliti menjadi sentral dari penelitian itu sendiri. Beranjak dari sifat keterbukaan dalam subjektifitas tadi, sesuai dengan apa yang seniman-seniman lakukan dalam kekaryaannya baik disadari atau tidak disadari.

Penelitian berbasis praktik ini tetap harus mengacu pada metode-metode para ahli untuk bisa dipertanggung jawabkan secara ilmiah. Metode yang sesuai dengan penelitian seni yang sedang saya lakukan nantinya akan mengacu kepada metode penciptaan Hawkins (1991). Sejalan dengan pedoman tersebut, metode penciptaannya meliputi: tahapan eksplorasi, improvisasi, dan perwujudan.

\section{HASIL DAN PEMBAHASAN}

Proses penciptaan karya akhir ini menggunakan berbagai persiapan, yaitu pengamatan dan pencarian data yang berkaitan dengan sikap pendaki gunung dalam kegiaan pendakian gunung, serta mencari informasi dari berbagai sumber, salah satunya melalui informasi media sosial, belajar dari karya-karya seniman, maupun fakta yang dilihat di lingkungan sekitar.

Pencarian ide dapat dilakukan dengan melakukan penelitian ke lapangan (studi lapangan). Sedangkan dalam Perwujudannya, penulis selalu mempertimbangkan unsur-unsur dan prinsip-prinsip seni rupa karena hal ini merupakan dasar dan pedoman dalam berolah estetis seorang perupa atau seniman saat sedang berkarya demi memperoleh hasil yang terbaik. (Ernawati, 2020) Selain elemen visual yang terdapat dalam karya seni rupa, faktor individu seniman selaku kreator di baliknya dapat pula ditinjau secara psikologis,dapat menjadi inspirasi dalam kekaryaannya.

\section{Karya Pertama}

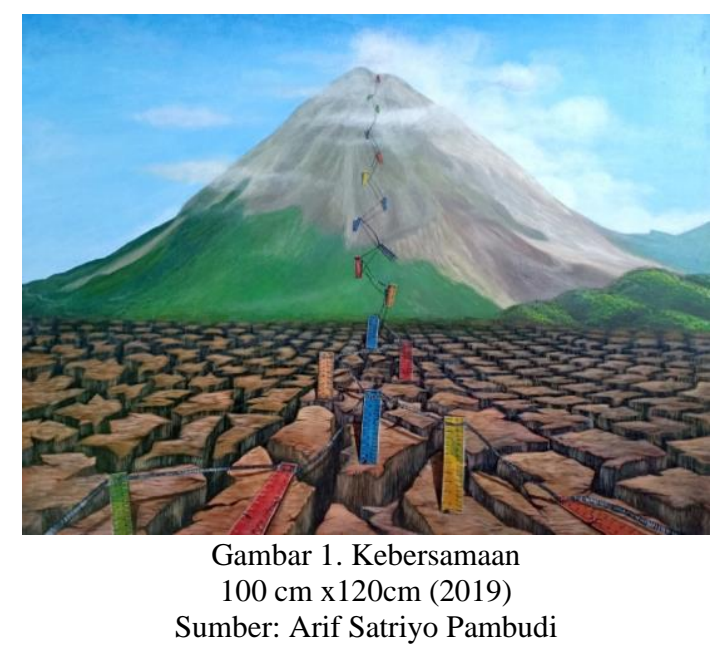

Karya "Kebersamaan" dengan objek penggaris berwarna-warni serta dalam kondisi ada yang berdiri tegap, miring dan rebah simbol dari keberbedaan kemampuan fisik, mental serta emosi yang berdiri di atas kondisi tanah yang retak-retak sebagai simbol rintangan-rintangan dalam pendakian yang menghadang namun keberbedaan itu berusaha untuk saling bersatupadu dan dijaga kebersamaannya dengan simbol tali yang saling mengikat penggarispenggaris satu dengan yang lainnya, dilukisan ini pula terdapat gunung sebagai simbol tujuan dan ambisi yang ingin bersama-sama ditaklukan.

Proses pengerjaan karya seni lukis ini, penulis menggunakan teknik sapuan tebal. Bahan utama atau medium karya yang penulis gunakan adalah kanvas, cat air. Karya lukis ini dibuat merujuk pada karya lukis bergaya surealis. 


\section{Karya Kedua}

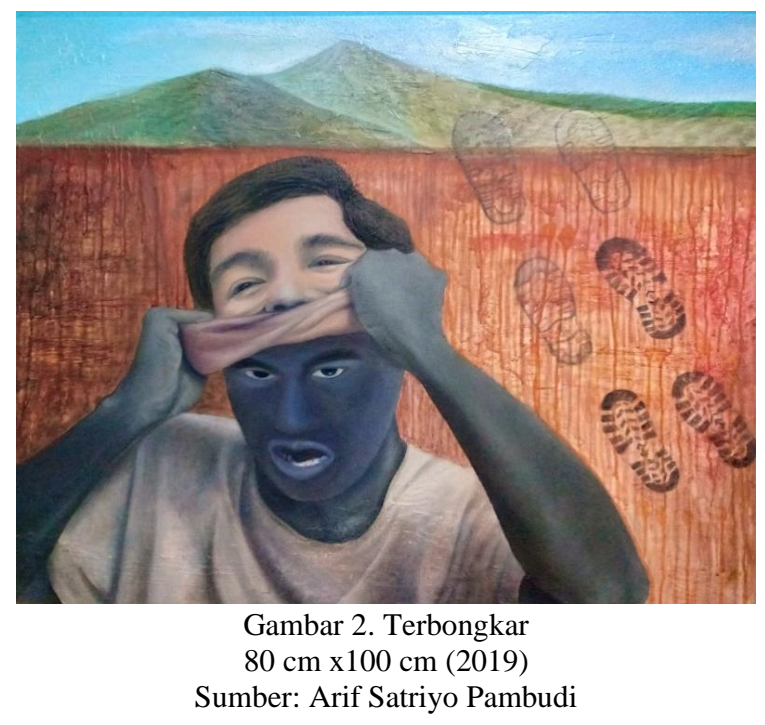

Karya dengan judul "Terbongkar" menampilkan subjek manusia (aki-laki). Karya ini memvisualisasikan tentang keterbongkaran sifat/karakter manusia yang sebenarnya ketika dalam pendakian gunung. Seorang laki-laki yang digambarkan dengan dua wajah disimbolkan sebagai manusia yang memiliki dua karakter. Wajah hitam disimbolkan sebagai karakter keburukan, sedangkan wajah dengan warna kulit disimbolkan sebagai karakter kebaikan. Gunung disimbolkan sebagai sesuatu yang bisa membokar dan menunjukkan karakter manusia yang sebenarnya. Dan jejak sepatu gunung disimbolkan sebagai proses pendakian.

Proses pengerjaan karya seni lukis ini, penulis menggunakan teknik sapuan tebal. Bahan utama atau medium karya yang penulis gunakan adalah kanvas, cat air. Karya lukis ini dibuat merujuk pada karya lukis bergaya surealis.

\section{Karya Kedua}

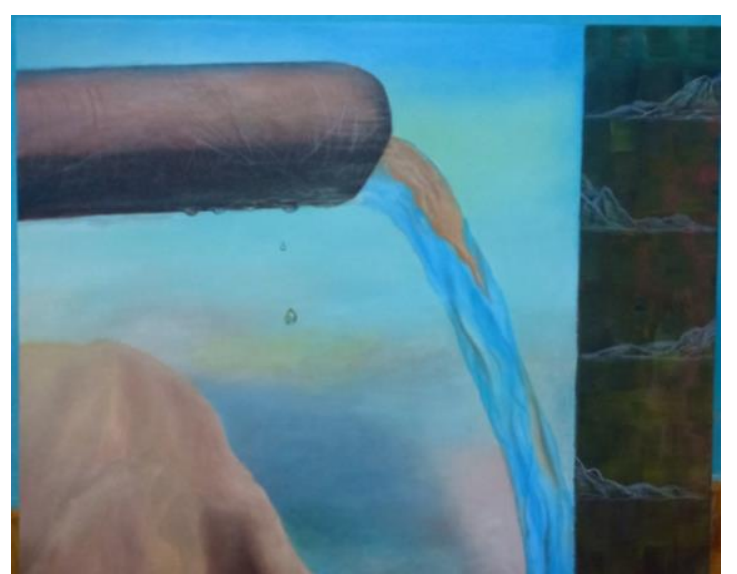

Gambar 3.Sumber Kehidupan

$100 \mathrm{~cm} \times 120 \mathrm{~cm}(2019)$

Sumber: Arif Satriyo Pambudi
Karya dengan judul "Sumber Kehidupan" menampilkan subjek pancuran air dan sketsa gunung di sebelah kanan. Karya ini dimaksudkan memvisualisasikan tentang arti sebuah sumber kehidupan yang tak lain adalah air, yang mana dalam kehidupan sehari-hari dan dalam situasi yang normal, air merupakan elemen yang sangat penting dalam kehidupan, tanpa air manusia, tumbuhan, dan hewan tidak bisa bertahan hidup, begitupula dalam situasi pendakian, air semakin terasa begitu berharga karena sebagai pelepas dahaga ketika dalam proses pedakian.

Dari hal itu semua penulis mampu menyadari arti sebuah kehidupan dan mampu mendorong manusia lainnya berfikir tentang rasa syukur tentang apa yang dimilikinya sekarang dan kehidupan yang dijalani sekarang tanpa harus selalu berambisi dan serakah untuk menggapai dan ingin memiliki sesuatu yang berlebihan

Proses pengerjaan karya seni lukis ini, penulis menggunakan teknik sapuan tebal. Bahan utama atau medium karya yang penulis gunakan adalah kanvas, cat air. Karya lukis ini dibuat merujuk pada karya lukis bergaya surealis.

\section{Karya Keempat}

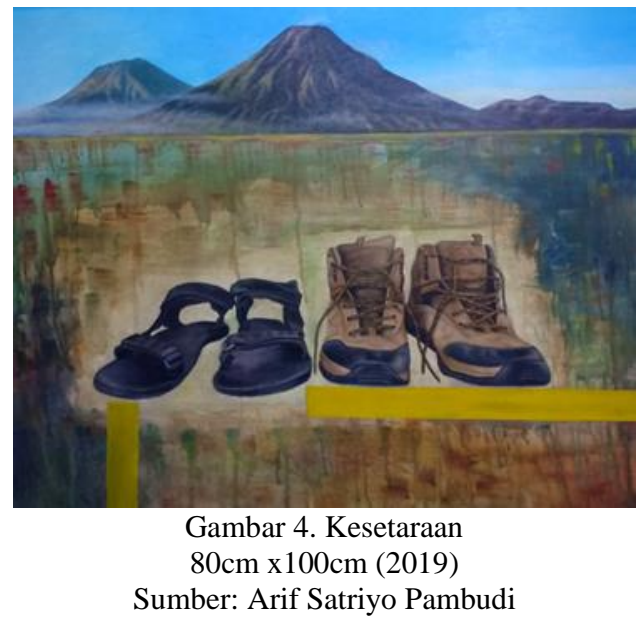

Karya dengan judul "kesetaraan" menampilkan objek sepatu gunung dan sandal gunung, sepatu sebagai simbol metafor suatu kalangan elite atau seseorang yang telah memiliki kemampuan lebih dalam hal materi, fisik maupun pengalaman sebagai orang yang berkecimpung di alam khususnya mendaki gunung sedangkan sandal gunung sebagai simbol metafor dari kalangan bawah atau seseorang yang kurang dalam hal materi, fisik maupun pengalaman dalam hal mendaki gunung, di sini objek sepatu tersusun dengan posisi yang sejajar dengan garis kuning sebagai simbol suatu kesejajaran dan membaurnya dari seluruh kalangan bawah dan atas tanpa pembeda-bedaan, sedangkan gunung di atas sebagai simbol sesuatu keadaan dan situasi yang mampu menunjukkan nilai-nilai sosial baik maupun buruk. 
Proses pengerjaan karya seni lukis ini, penulis menggunakan teknik sapuan tebal. Bahan utama atau medium karya yang penulis gunakan adalah kanvas, cat air . Karya lukis ini dibuat merujuk pada karya lukis bergaya surealis.

\section{Karya Kelima}

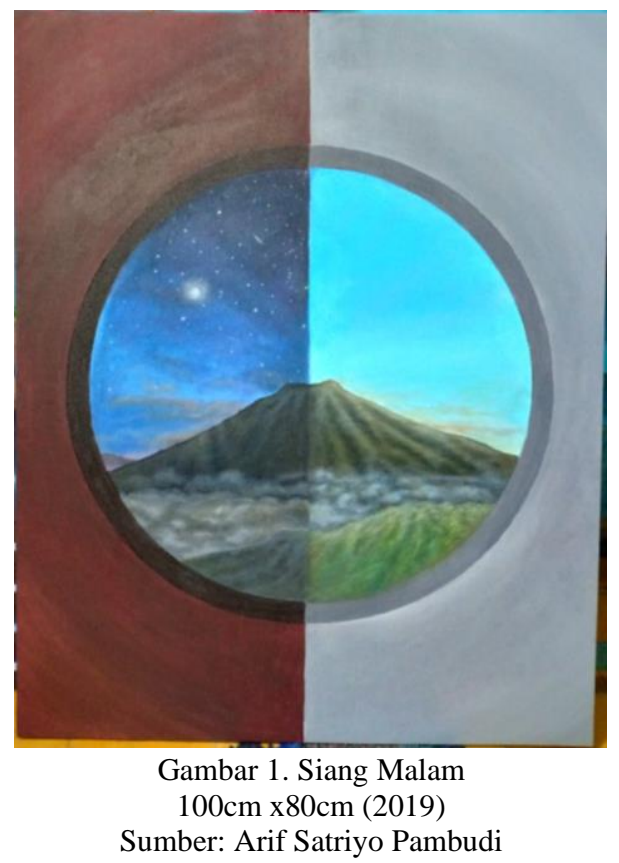

Karya dengan judul "Siang Malam" mmvisualisasikan pemandangan gunung dengan dua situasi waktu, yaitu siang dan malam dengan background merah dan putih, di sekelilingnnya. Yang ingin penulis ungkapkan dari Pemandangan gunung tersebut dengan situasi malam dan siang merupakan dua situasi yang amat berbeda dan dari situasi gunung yang malam dan siang di situasi tersebut manusia mampu mengambil ilmu dan mampu mengajarkan suatu nilai-nilai yang mana ketika dalam situasi siang hari para pendaki mampu dengan mudahnya memandang trek ditambah ketika telah sampai di puncak mampu menikmati pemandangan yang amat mempesona dengan tenangnnya dari kemudahan dan kenikmatan yang dirasakan itu mampu menyadarkan rasa kesyukuran manusia akan ciptaan Tuhan yang amat mengagumkan dan begitu indah dan dari bagian situasi yang siang tersebut terdapat background putih sebagai simbol suatu kesucian hati yang mana rasa syukur akan nikmat Tuhan itu haruslah berlandaskan keilkhlasan dari hati yang terdalam.

Sedangkan pemandangan gunung dengan situasi malam tersebut penulis ingin mengungkapkan bagaimana dalam situasi pendakian malam hari yang gelap sepi dan mencekam di sana para pendaki di ajarkan menjadi manusia yang waspada namun penuh kepasrahan kepada yang Kuasa, dan pada bagaian situasi malam hari terdapat background merah merupakan simbol dari keberanian yang di ajarkan alam/gunung kepada setiap para pendaki.
Proses pengerjaan karya seni lukis ini, penulis menggunakan teknik sapuan tebal. Bahan utama atau medium karya yang penulis gunakan adalah kanvas, cat air. Karya lukis ini dibuat merujuk pada karya lukis bergaya surealis

\section{Karya Keenam}

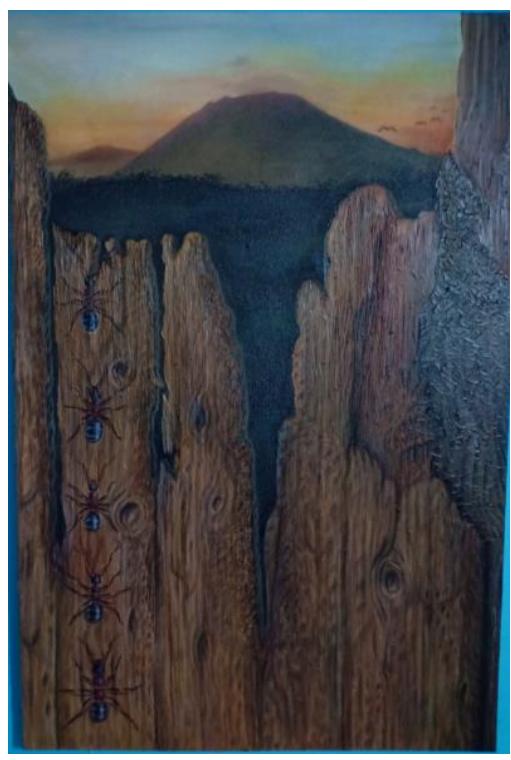

Gambar 6. Semut Kecil

$80 \mathrm{~cm} \times 110 \mathrm{~cm}(2019)$

Sumber: Arif Satriyo Pambudi

Karya dengan judul "Semut Kecil" menampilkan objek semut yang sedang merayap di sebuah kayu, dan ada pula pemandangan gunung ketika senja. Dari lukisan yang ad tersebut penulis ingin mengungkapkan sebuah nilai-nilai pendakian, dan mengapa dalam lukisan tersebut terdapat semut yang sedang merayap di kayu, di dalam lukisan itu penulis memetaforkan manusia atau para pendaki layaknya seekor semut, bagaimana semut merupakan makhluk yang kecil namun memiliki sisi ketangguhan, bagaimana semut mampu mendaki dengan tangguh sebuah dinding tinggi, gedung atau pohon yang tingi menjulang yang penulis simbolkan dengan kayu pada lukisan, semut juga mampu membangun rumah yang besar berkali-kali lipat di bandingkan ukuran tubuhnnya, dan dari sisi lain semut mampu nilai pula sebagai makhluk yang rentan atau lemah, seperti contoh: ketika semut yang kecil rentan mati karna terpijak, atau tersapu benda-benda yang lebih besar darinya.

Dari situlah penulis mengambil nilai-nilai seekor tersebut yang penulis jadikan objek metafor dari manusia atau pendaki, yang mana manusia jika dibandingkkan ukurannya dari sebuah gunung amatlah jauh berbeda, namun dengan sisi ketangguhan dan pemikiran cerdasnnya manusia mampu menakhlukan gunung yang tinggi dengan kekuatannya, namun manusia memiliki sisi kelemahan sama halnya dengan semut. 
Dari nilai-nilai yang ada tersebut penulis ingin juga memberikan pandangan agar nantinyya mampu menyadarkan pada setiap pendaki maupun orang-orang bahwa sebenarnnya manusia bukanlah makhluk yang sempurna dan tangguh seutuhnya namun manusia juga memiliki sisi kelemahan dan amat banayak kekurannya dan amat kecil manusia di muka bumi ini jadi tidaklah pantas untuk menyombongkan harta atau tahta yang di raih dalam hidupnnya, kecuali mensyukurinya dan berpasrah kepada yang Maha Kuasa.

Proses pengerjaan karya seni lukis ini, penulis menggunakan teknik sapuan tebal. Bahan utama atau medium karya yang penulis gunakan adalah kanvas, cat air dan menggunakan mix media berupa tambahan dempul tembok sebagai tekstur pada kanvas. Karya lukis ini dibuat merujuk pada karya lukis bergaya surealis

\section{KESIMPULAN}

Konsep Karya Seni ini berawal dari keinginan pelukis mengungkap nilai-nilai sosial yang terkandung dalam pendakian gunung, yang mana dalam pendakian gunung sesungguhnya bukanlah hanya sebuah kegiatan rekreasi atau olahraga semata, namun dibalik itu banyak sekali terkandung nilai-nilai sosial yang mampu dijadikan inspirasi dan di terapkan di kehidupan seharihari, seperti nilai kebersamaan, kesetiaan, tenggang rasa, kejujuran. Melalui bahasa visual dan ditunjang unsur-unsur seni lukis dan unsur psikis penulis menggambarkan bagaimana yang sesungguhnya.

Lukisan dengan objek alam,manusia dan benda ini disajikan melalui gaya surealis. Lukisan yang dihasilkan berjumlah 6 buah dengan berbagai ukuran. Karya-karya tersebut tercipta lukisan yang berjudul kebersamaan dengan ukuran $(100 \times 120 \mathrm{~cm})$, dan karya selanjutnya adalah terbongkar dengan ukuran $(80 \mathrm{x} 100$ $\mathrm{cm})$, sumber kehidupan dengan ukuran $(80 \times 100 \mathrm{~cm}$ ), siang malam dengan ukuran $(80 \times 100 \mathrm{~cm})$ kesetaraan dengan ukuran $(80 \times 100 \mathrm{~cm})$, semut kecil dengan ukuran $(80 \times 110 \mathrm{~cm})$.

\section{DAFTAR PUSTAKA}

Bahari, Nooryan. (2008). Kritik Seni: Wacana, Apresiasi dan Kreasi. Yogyakarta: Pustaka Pelajar.

Emir. (2019). Usung Tema Folklore dalam Show time Gelar Cipta Tata Rias 2019. diakses 8 Juni 2019, dari https://www.unesa.ac.id/usung-tema-

Abdurrahman, Rifqi. (2015). ProfilVo2 Max dan Profil Mental Toughness Pendaki PAMOR 14 PEAKS EXPEDITION IV. Bandung: UPI.

Aprilia, Annisa. (2017, Juli 18). Sederet Manfaat Mendaki Gunung bagi Kesehatan, Salah Satunya Bikin Hidup Lebih Bahagia. Okezone LifeStyle. https://lifestyle.okezone.com/read/2017/07/1 8/481/1738682/sederetmanfat-mendakigunung-bagi-kesehatan.

Anna, Lusia Kus. (2017, Juli 13). Melepas stres dengan Mendaki Gunung. Kompas.com. https://lifestyle.kompas.com/read/2017/07/13 /170000620/melepas-stres-dengan-mendakigunung.

Budiwirman. (2012). Seni Seni Grafis, dan Aplikasinya dalam Pendidikan. Padang: UNP Press.

Cauto, Minarsih. (2009). Seni Rupa Teori dan Aplikasi. Padang: UNP Press Padang.

Ernawati, E. (2020). Psikologis Dalam Seni: Katarsis Sebagai Representasi Dalam Karya Seni Rupa. DESKOVI: Art and Design Journal, 2(2), 105112.

Hanula, M. Suoronta, J. Vaden, T. (2005), Artistic Research Theoris, Methods, And Practice. Findland : Cosmoprint Oy

Rahardjo, Buddy. (1984). Pendidikan Seni Rupa untuk Kurikulum 1984. Bandung: CV Yrama.

Soedarso, Sp. (2006). Trilogi Seni Penciptaan Eksistensi Dan Kegunaan, Yogyakarta: ISI Yogyakarta.

Soetjipto, Katjik. (1989). Sejarah Perkembangan Modern. Jakarta: P2LPTK.

Zubaedi. (2005). Pendidikan Berbasis Masyarakat. Yogyakarta: Pustaka Pelajar 
Arif Satriyo Pambudi / DESKOVI : Art and Design Journal, Vol. 3, No.1, Juni 2020, 43-48

(Halaman ini sengaja dikosongkan) 